\title{
Kajian efektivitas kapasitas kerja pada kegiatan pemeliharaan common area di Kawasan Pariwisata The Nusa Dua, Bali
}

\author{
Desy Fatmala Makhmud ${ }^{1 *}$, Daisy Radnawati ${ }^{1}$, Ray March Syahadat ${ }^{1}$ \\ 1. Program Studi Arsitektur Lanskap, Fakultas Teknik Sipil dan Perencanaan, Institut Sains dan \\ Teknologi Nasional \\ *E-mail: desyfatmala04@gmail.com
}

\begin{abstract}
Study on the Effectiveness of Work Capacity in Common Area Maintenance Activities in The Nusa Dua Tourism Area, Bali. Maintenance of Green Open Space (RTH) in an area is very important to do. In the current development of tourism, the existence of a good green space will not only improve the quality of the surrounding environment, but also can increase the sale value of an area if managed effectively and efficiently. The Nusa Dua tourism area managed by PT ITDC is an international tourist destination that has natural resources and good landscape management. RTH (Common Area) maintenance work is the main focus for The Nusa Dua Field Maintenance Unit (UPL). To determine the appropriateness of the standards for The Nusa Dua landscape maintenance work, a study will be conducted on the Effectiveness of Work Capacity of each type of maintenance work in the Common Area (CA) block. The study is limited to the Common Area 1-6 block, Nusa Dharma Island and Peninsula Island. The maintenance work that will be discussed is daily routine work by CA block workers. The stages start from preparation, data collection, analysis, and synthesis. Data collection techniques were carried out by means of observation, interviews, and literature studies. Data were analyzed qualitatively and quantitatively. The results obtained indicate the number of workers is still not in accordance with the standards in CA maintenance activities.
\end{abstract}

Keywords: Environmental Quality, Green Open Space, Landscape Management.

\section{Pendahuluan}

The Nusa Dua adalah destinasi wisata internasional yang ramai dikunjungi wisatawan asing maupun domestik karena kawasan ini memiliki daya tarik alam serta pengaturan lanskap yang baik (Wijayanti, 2000). Kawasan seluas 350 Ha ini memiliki area hijau (nonsaleable area) seluas \pm 43 ha yang biasa disebut sebagai Common Area. Berada tersebar di seluruh kawasan, area ini ditanami 6.080 pohon, yang terdiri dari berbagai jenis tanaman, termasuk sebanyak 2.899 pohon berkategori langka. Pengembangan dan pengelolaan kawasan ini dilakukan oleh PT Pengembangan Pariwisata Indonesia (Persero) atau Indonesia Tourism Development Corporation (ITDC).

Undang-Undang No. 9 Tahun 1990 tentang Kepariwisataan menjelaskan bahwa perlu adanya langkahlangkah pengaturan yang dapat mewujudkan keterpaduan dalam penyelenggaraan kepariwisataan serta memelihara kelestarian dan mendorong upaya peningkatan mutu lingkungan hidup serta obyek dan daya tarik wisata. Untuk itu diperlukan suatu kegiatan pengelolaan lingkungan The Nusa Dua khususnya pada Common Area (CA), yang tidak hanya berfungsi komersil tetapi juga untuk menjaga nilai estetis sekaligus meningkatkan mutu kawasan agar tidak memberikan dampak negatif kepada lingkungan sekitar.

Berdasarkan hasil pengamatan selama studi, dalam kegiatan pemeliharaan CA di kawasan The Nusa Dua, terdapat beberapa kegiatan rutin yang dilakukan oleh tenaga pemeliharaan seperti pembersihan, pemupukan, pemangkasan, penyiangan, penyiraman hingga penggemburan. Semua kegiatan ini sudah sangat baik dilaksanakan oleh masing-masing tenaga kerja pada tiap blok, hanya saja masih terdapat beberapa permasalahan seperti pada beberapa blok CA terdapat tanaman yang mati karena kurang mendapatkan asupan air, erdapat tanaman liar yang mengganggu tanaman utamanya, penataan semak yang belum maksimal, hingga tenaga kerja yang tidak menggunakan jam kerja secara maksimal. Perbedaan kemampuan juga menjadi pembeda dari hasil pemeliharaan pada tiap blok CA.

Berdasarkan hal tersebut, maka akan dilakukan penghitungan Efektivitas Kapasitas Kerja (EKK) dalam kegiatan pemeliharaan CA di kawasan The Nusa dua, apakah sudah sesuai antara jumlah tenaga kerja 
terhadap luasan area serta jenis pekerjaan pemeliharaan yang dilakukan, penghitungan standar kapasitas pekerjaan juga dirata-ratakan sesuai dengan kemampuan seluruh pekerja pemeliharaan CA. Melalui kajian ini diharapkan dapat memberikan suatu gambaran tentang pengelolaan pemeliharaan RTH yang dapat mewujudkan hasil yang cukup efektif untuk menghasilkan kualitas yang diharapkan.

\subsection{Kerangka Pikir}

Penelitian dimulai dengan mengetahui ruang lingkup pekerjaan, dimulai dari luasan area kegiatan, volume dan waktu pemeliharaan, kemudian dilakukan penghitungan standar kapasitas pekerjaan untuk dilanjutkan pada penghitungan total jam kerja dari masing-masing blok pemeliharaan menggunakan rumus yang telah ditetapkan, setelah itu akan didapatkan jumlah kebutuhan tenaga kerja dan rasio ideal pada kegiatan pemeliharaan di blok CA kawasan The Nusa Dua (Gambar 1).

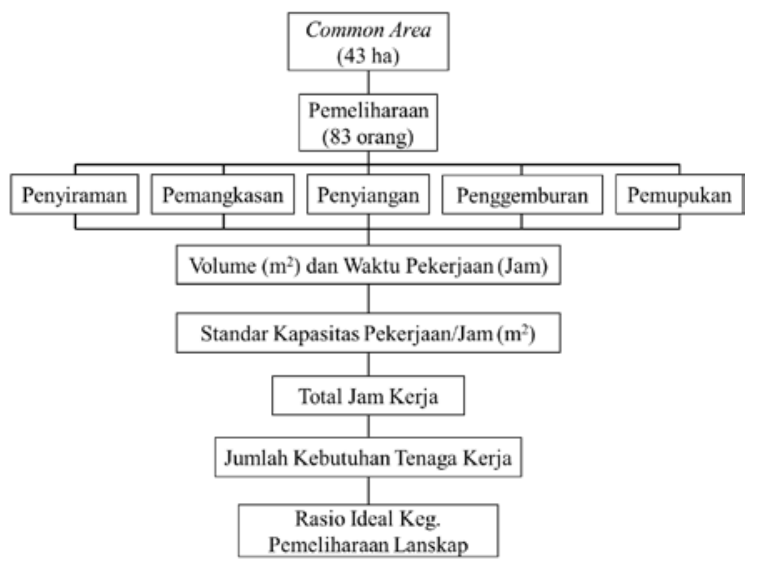

Gambar 1. Kerangka Berfikir

(Sumber: Hasis analisis, 2019)

\section{Metode}

\subsection{Tempat dan Waktu Penelitian}

Penelitian dilaksanakan di kawasan pariwisata The Nusa Dua, yang dikelola oleh PT Pengembangan Pariwisata Indonesia (Persero), Indonesia Tourism Development Corporation (ITDC) Bali, disajikan dalam Gambar 2. Pengambilan data dilakukan selama 3 bulan, yang dimulai pada tanggal 1 Oktober hingga 24 Desember 2018, dalam penghitungan kapasitas kerja setiap orang tidak dipengaruhi oleh tahun pengambilan data, tetapi oleh keahlian dan ketentuan yang ada di lingkungan kerja (Putra et al, 2017).

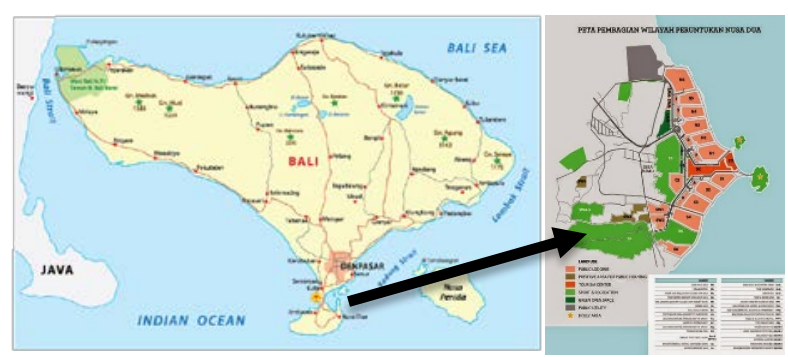

Gambar 2. Peta Pulau Bali dan Peta Kawasan Pariwisata The Nusa Dua.

(Sumber: Google.com, 2018)

\subsection{Metode Penelitian}

Metode yang dilakukan yaitu observasi langsung dan partisipasi aktif di kawasan The Nusa Dua. Studi dibatasi pada blok Common Area 1-6, Pulau Nusa Dharma dan Pulau Peninsula. Tahapan penelitian dimulai 
dari persiapan, pengumpulan data, analisis, dan sintesis. Teknik pengumpulan data dilakukan dengan cara observasi, wawancara, dan studi literatur.

Data yang didapatkan dari hasil observasi yaitu perhitungan jumlah pekerja, luas area pemeliharaan, volume pekerjaan, kapasitas pekerjaan, lama pelaksanaan dan intensitas pekerjaan pemeliharaan. Kegiatan wawancara dilakukan kepada pihak pekerja serta staf Unit Pemeliharaan Lapangan (UPL). Sedangkan studi literatur digunakan untuk memperoleh standar, teori dan ketetapan, serta hasil-hasil penelitian pengelolaan kawasan RTH. Data yang dikumpulkan kemudian dianalisis baik secara kualitatif maupun kuantitatif. Efektivitas kapasitas kerja dianalisis dengan menggunakan formula dari Febriani (1998). Pendekatan ini juga pernah dilakukan oleh Dlukha et al. (2017), dalam menghitung efektivitas kapasitas kerja pada area hazard lapangan golf. Adapun formula yang digunakan yaitu sebagai berikut:

\section{$\mathrm{TJK}=\mathrm{VK} / \mathrm{KK} \times \mathrm{P}$}

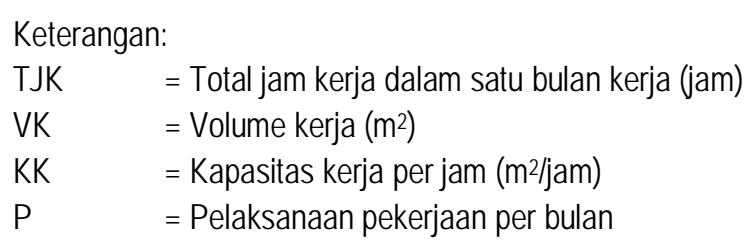

Untuk mendapatkan standar kapasitas kerja, dilakukan pengambilan sampel sebanyak 3 orang dari masing-masing jenis pekerjaan di setiap blok CA, dilakukan penghitungan lama pekerjaan (jam) terhadap luas dari masing masing jenis pekerjaan pemeliharaan $\left(\mathrm{m}^{2}\right)$ kemudian dijumlahkan dan dihitung rata-rata nya.

Setelah itu hitung Total Jam Kerja (TJK) menggunakan rumus di atas, JK yang telah dihitung dibagi dengan total jumlah jam kerja pemeliharaan kawasan CA selama satu bulan, maka hasilnya akan diketahui standar jumlah tenaga kerja yang dibutuhkan untuk kegiatan pemeliharaan CA di kawasan The Nusa Dua.

Untuk mencari rasio perbandingan pekerjaan yaitu dengan cara, membagi luas area kawasan The Nusa Dua yang akan dipelihara dengan standar jumlah tenaga kerja yang telah ditemukan dari hasil perhitungan diatas. Perbandingan rasio yang ideal adalah 1:0,1 sampai 1:0,3 yang artinya setiap satu orang pekerja memiliki area yang harus dipelihara seluas 0.1 sampai dengan 03 ha (Febriani, 1989).

\section{Hasil dan Pembahasan}

\subsection{Kondisi Umum}

PT Pengembangan Pariwisata Indonesia (Persero) atau Indonesia Tourism Development Corporation (ITDC) berdiri pada tahun 1969, merupakan BUMN pengembang dan pengelola kawasan pariwisata Indonesia, salah satunya adalah The Nusa Dua, Kawasan ini terletak di tenggara pulau Bali, dengan luas area The Nusa Dua mencapai $350 \mathrm{Ha}$ yang terbagi dalam dua area yaitu Saleable Area seluas 309 ha dan Common Area (CA) atau ruang terbuka bersama (nonsaleable) seluas 43 ha (Gambar 3). Saleable area dikelola oleh masingmasing investor sedangkan CA dikelola langsung oleh ITDC (ITDC, 2017).

Ruang Terbuka Hijau yang disebut dengan Common Area (CA) ini dibagi menjadi beberapa zona Pemeliharaan yaitu, Common Area 1, Common Area 2, Common Area 3, Common Area 4, Common Area 5, Common Area 6, Pulau \& taman hutan, Perumahan direksi \& Puja Mandala, dan Kantor pusat (Gambar 4). Dalam pelaksanaan pemeliharaannya, ITDC menyerahkan hampir seluruh area CA kepada Koperasi Nusa Jaya yang bertindak sebagai outsourcing terhadap tenaga kerja pemelihara Common Area.

Biaya pemeliharaan CA The Nusa Dua bersumber dari pembayaran iuran kawasan (assessment cost) yang dilaksanakan oleh masing-masing investor kepada ITDC yang dibagi secara proporsional berdasarkan luas area atau jumlah kamar yang diijinkan (allowable room). 

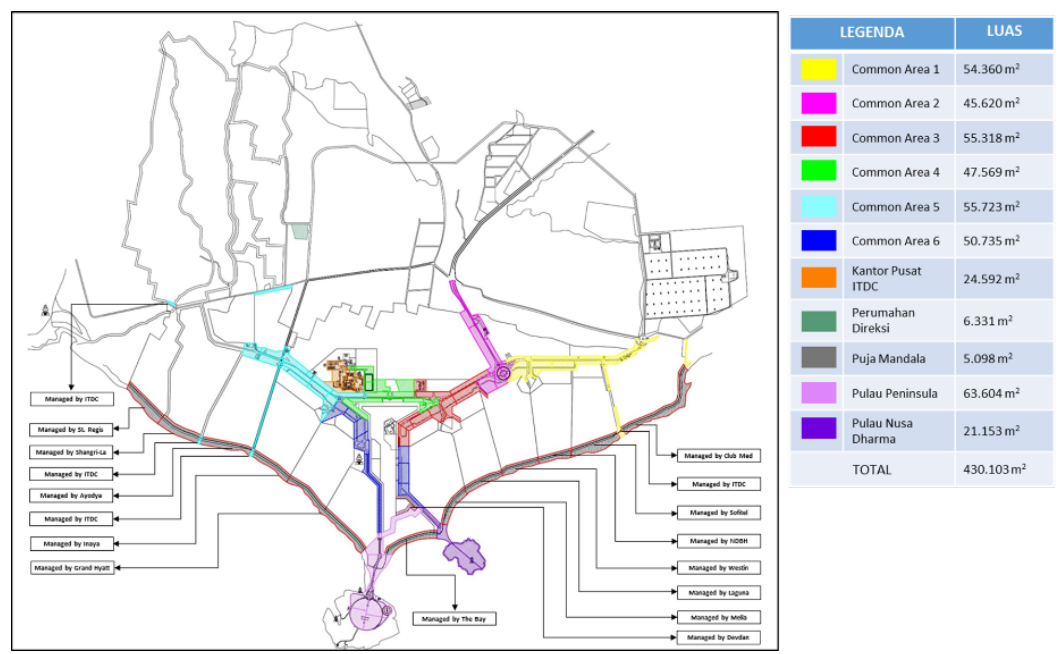

Gambar 3. Common Area dan Saleable Area The Nusa Dua

(Sumber: hasis pengamatan, 2018)

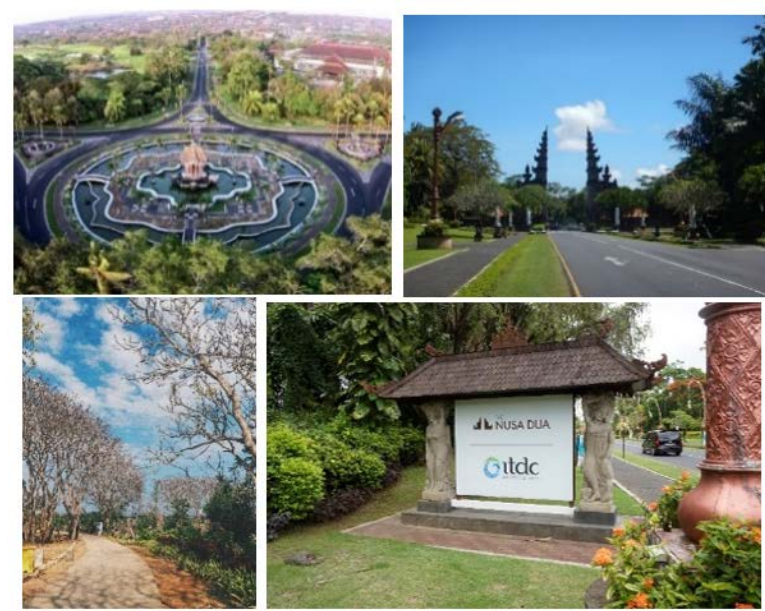

Gambar 4. Common Area di Kawasan The Nusa Dua (Sumber: hasil dokumentasi, 2018)

\subsection{Struktur Organisasi Perusahaan.}

Kegiatan pemeliharaan CA berada pada seksi pemeliharaan lapangan (Gambar 5).

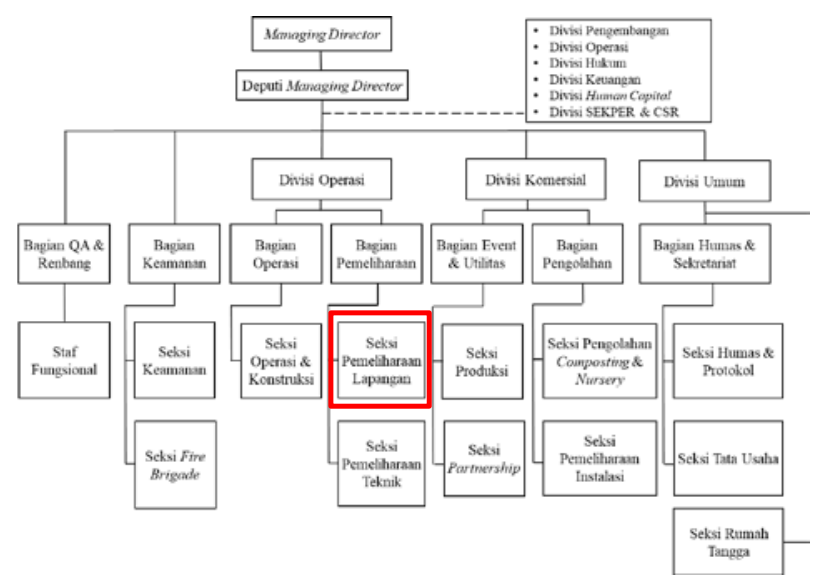

Gambar 5. Struktur organisasi The Nusa Dua

(Sumber: Hasil pengamatan, 2018) 
Unit Pemeliharaan (UPEM) terbagi atas Unit Pemeliharaan Lapangan (UPL) dan Unit Pemeliharaan Teknis (UPT), kegiatan pengelolaan pemeliharaan bagian lanskap pada tiap blok CA berada dibawah tanggung jawab UPL (Gambar 6).

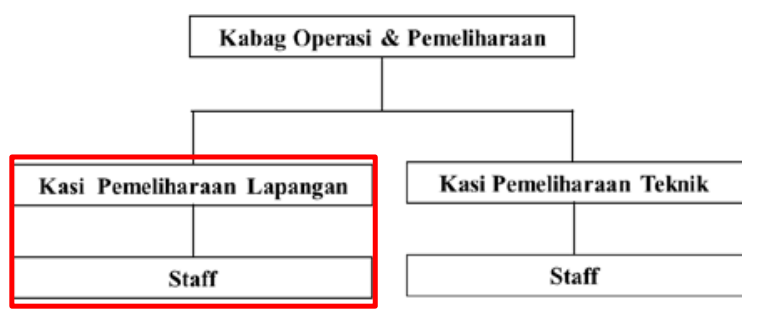

Gambar 6. Struktur Organisasi Bagian Pemeliharaan

(Sumber: Hasil pengamatan, 2018)

\subsection{Tenaga dan Area Pemeliharaan Common Area}

Luas RTH yang dikerjasamakan dan menjadi tanggung jawab penyedia jasa untuk memeliharanya adalah seluas $430.103 \mathrm{~m} 2$ yang dibagi menjadi 11 bagian dengan total jumlah tenaga adalah 125 orang (Tabel 1) (Gambar 7).

Berdasarkan hasil pengamatan di kawasan The Nusa Dua, beberapa kegiatan yang rutin dilakukan pada tiap blok oleh tenaga CA yaitu penyiraman, pemangkasan, penyiangan, penggemburan, pemupukan dan pembersihan/penyapuan.

Tabel 1. Luas Area Pemeliharaan Common Area dan Jumlah Tenaga

\begin{tabular}{|c|c|c|c|}
\hline No & Area & Luas $\left(\mathrm{m}^{2}\right)$ & Jumlah Tenaga \\
\hline 1 & CA 1 & 54.360 & 12 \\
\hline 2 & CA 2 & 45.620 & 9 \\
\hline 3 & CA 3 & 55.318 & 10 \\
\hline 4 & CA 4 & 47.569 & 12 \\
\hline 5 & CA 5 & 55.723 & 13 \\
\hline 6 & CA 6 & 50.735 & 11 \\
\hline 7 & Pulau Besar dan Kecil & 84.757 & 16 \\
\hline 8 & Perumahan Direksi & 6.331 & 3 \\
\hline 9 & Puja Mandala & 5.098 & 3 \\
\hline 10 & Kantor Pusat & 24.592 & 7 \\
\hline \multirow[t]{11}{*}{11} & Tenaga Khusus & & \\
\hline & a. Pengawas & - & 2 \\
\hline & b. Penyulaman & - & 2 \\
\hline & c. Pembersih Pantai & - & 5 \\
\hline & d. Pengangkutan sampah & - & 8 \\
\hline & e. Sprinkler & - & 3 \\
\hline & f. Pangkas widelia & - & 2 \\
\hline & g. Pembersih Signboard & - & 1 \\
\hline & h. Pembersih Kolam & - & 2 \\
\hline & $\begin{array}{l}\text { i. Pembersih kelapa \& } \\
\text { palem }\end{array}$ & - & 4 \\
\hline & Total & 430.103 & 125 \\
\hline
\end{tabular}

(Sumber: Hasil pengamatan, 2018)

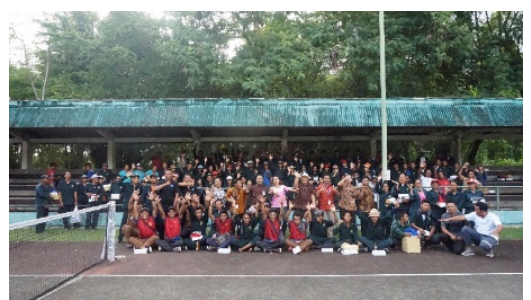

Gambar 7. Pegawai UPL dan Tenaga Pemeliharaan The Nusa Dua

(Sumber: Hasil dokumentasi, 2018) 


\subsection{Tugas dan Tanggung Jawab Tenaga Blok CA}

Tenaga kerja melakukan pekerjaan pemeliharaan dimulai pukul 06.00-10.00 WITA, dilanjut pukul 14.00-17.00 WITA (selama 7 jam) setiap hari, waktu bekerja dalam seminggu adalah sebanyak 6 hari dengan libur 1 hari secara bergantian, maka dalam waktu satu bulan tiap pekerja pemeliharaan pada blok CA ini bekerja selama $168 \mathrm{jam}$, dengan rincian pekerjaan sebagai berikut:

1. Pembersihan/ Penyapuan Areal

Pada tiap harinya, pembersihan/penyapuan blok CA di kawasan The Nusa Dua sudah cukup baik pada tiap blok CA, terlihat dari waktu penyapuan yang sudah sesuai dengan prosedur pekerjaan pemeliharaan The Nusa Dua yaitu dua kali sehari, penyapuan dilakukan pukul 06.00 WITA sebelum para wisatawan berlalulalang, dan tetap dilakukan pembersihan ketika kawasan pada siang-sore hari (Gambar 8).
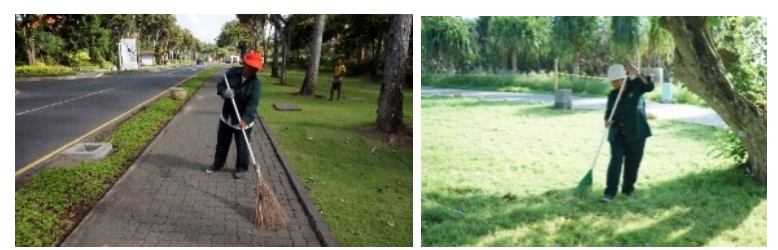

Gambar 8. Penyapuan Area Jalan (kiri) dan Penyapuan Area Rumput (kanan)

(Sumber: Hasil dokumentasi, 2018)

\section{Penyiraman Tanaman dan Rumput}

Kegiatan penyiraman blok CA di kawasan The Nusa Dua sudah cukup sesuai dengan standar prosedur kegiatan, penyiraman dilakukan pada pagi dan sore hari pada pangkal tanaman atau tanah dipangkal pohon. Namun masih perlu penyiraman yang lebih intens pada tanaman-tanaman yang baru ditanam agar tidak layu dan mati. Selain itu, tidak ada penyiraman tanaman pada siang hari, karena akan menyebabkan terbakarnya daun yang kena air, karena teriknya matahari. Setelah menyiram, pekerja selalu merapikan selang kembali, digulung dan diletakkan di titik yang tidak terlalu terlihat oleh pengunjung (Gambar 9).
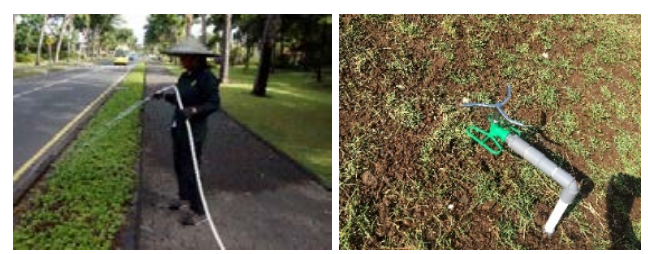

Gambar 9. Penyiraman Menggunakan Selang \& Sprinkler

(Sumber: Hasil dokumentasi, 2018)

\section{Penyiangan Tanaman}

Penyiangan tanaman pengganggu pada blok CA di kawasan The Nusa Dua sudah cukup optimal pada beberapa bagian $C A$, dilakukan dua kali sebulan secara periodik dengan melihat kondisi dari tanaman tersebut. Namun pada beberapa blok CA lainnya masih terdapat tanaman liar yang tumbuh mengganggu tanaman utama, hal ini terjadi karena pekerja kurang memaksimalkan waktu dalam bekerja dan pencabutan tanaman pengganggu yang tidak sampai ke akar. Hal ini menjadi usulan bagi pengawas lapangan untuk lebih memperhatikan kegiatan penyiangan oleh pekerja pemeliharaan di beberapa bagian CA (Gambar 10).

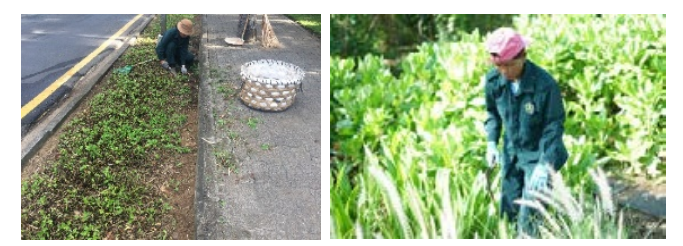

Gambar 10. Penyiangan di Tanaman Utama

(Sumber: Hasil dokumentasi, 2018) 


\section{Penggemburan Tanaman}

Pekerjaan penggemburan di blok CA kawasan The Nusa Dua sudah dilakukan dengan baik, setiap pekerja sudah menguasai kegiatan ini sesuai dengan ketentuan yang ada. Hal ini dibuktikan dengan kesesuaian langkah-langkah pekerjaan dan waktu pelaksanaan yaitu, sebelum melakukan penggemburan, pekerja akan menyiram tanah terlebih dahulu agar tekstur tanah menjadi lebih gembur. Penggemburan dilakukan dengan cara membalik tanah yang tadinya berada di bagian atas menjadi di bagian bawah dan sebaliknya. Pelaksanaan kegiatan ini dilakukan sebulan sekali secara periodik, atau sesuai dengan kondisi tanaman tersebut. (Gambar 11).
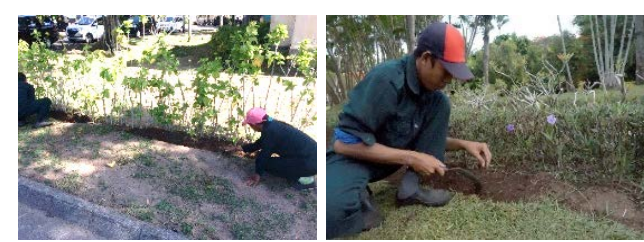

Gambar 11. Penggemburan Tanaman

(Sumber: Hasil dokumentasi, 2018)

\section{Pemupukan Tanaman dan Rumput}

Pelaksanaan kegiatan pemupukan tergantung dari jenis tanaman yang dipupuk. Untuk tanaman pohon dilakukan setahun sekali, sedangkan tanaman semak dan perdu setiap 6 bulan sekali, dan jenis ground cover dan rumput setiap 1 tahun sekali. Kebutuhan pupuk pada masing-masing blok CA di kawasan The Nusa Dua dihitung berdasarkan luasan semak dan jumlah pohon di masing-masing blok tenaga CA disesuaikan juga dengan Rencana Kerja dan Anggaran Perusahaan (RKAP). Pemupukan berjalan dengan baik, sesuai dengan ketentuan dan jadwal rutin yang telah dibuat oleh UPL (Gambar 12).
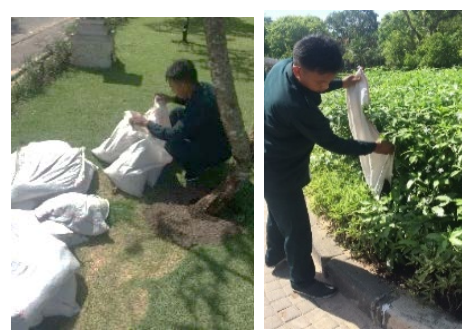

Gambar 12. Pemberian Pupuk Kompos pada Semak.

(Sumber: Hasil dokumentasi, 2018)

\section{Pemangkasan Semak dan Pohon}

Pemangkasan pohon yang dilakukan oleh tenaga dari luar koperasi sudah cukup kompeten, dari segi teknik sudah sesuai prosedur pemangkasan pohon, hanya saja mereka tidak menggunakan peralatan K3 selama berkegiatan, hal ini sebenarnya cukup berbahaya bagi keselamatan. Untuk pemangkasan semak oleh tenaga CA, sudah sangat baik terlihat dengan kesesuaian waktu pemangkasan, teknik pemangkasan, dan hasil pembentukan semak yang terlihat rapi dan indah, hanya bagi tenaga baru masih perlu pengarahan oleh ketua kelompok agar lebih terampil (Gambar 13).

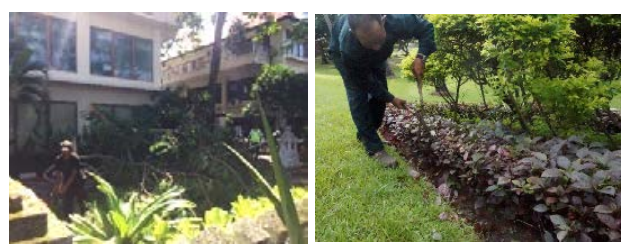

Gambar 13. Pemangkasan Pohon dan Semak

(Sumber: Hasil dokumentasi, 2018) 


\section{Pemangkasan Rumput.}

Tenaga yang mendapat tugas memangkas rumput adalah tenaga yang sudah terlatih menggunakan alat/mesin potong rumput, pada hal ini biasa dilakukan oleh masing-masing ketua kelompok blok CA. Tenaga tersebut mengambil alat potong rumput yang disimpan di gudang mesin unit pemeliharaan termasuk meminta bahan bakarnya kepada pengawas unit pemeliharaan.

Tenaga potong rumput di masing-masing CA secara bergantian menggunakan berbagai jenis mesin potong rumput, sehingga rumput semua area tetap terlihat rapi dan dipotong sesuai jadwal (Gambar 14). Pemotongan rumput dilakukan dari pukul 06.00 WITA hingga selesai dan dilanjutkan pada pukul 14.00 hingga selesai sebanyak 2 kali dalam sebulan.
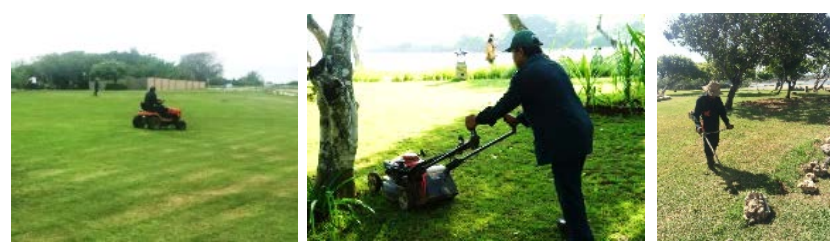

Gambar 14. Pemangkasan Rumput

(Sumber: Hasil dokumentasi, 2018)

\subsection{Efektivitas Kapasitas Kerja}

Berdasarkan hasil pengamatan, beberapa kegiatan yang rutin dilakukan pada tiap blok oleh tenaga CA yaitu penyiraman, pemangkasan, penyiangan, penggemburan, pemupukan dan pembersihan/penyapuan. Blok yang dihitung adalah CA 1 hingga 6, Pulau Nusa Dharma dan Peninsula seluas $394.082 \mathrm{~m}^{2}$, dengan jumlah tenaga yang bekerja pada tiap blok sebanyak 83 orang (Tabel 2).

Rasio tenaga kerja yang ditetapkan The Nusa Dua adalah $0,47 \mathrm{Ha}$, yang artinya tiap satu orang pekerja memiliki area yang harus dipelihara seluas $0,47 \mathrm{Ha}$. Luas area pemeliharaan ini sudah cukup mendekati perbandingan ideal yang berkisar antara 1:0,1 sampai 1:0,3 (Febriani, 1998). Hal ini masih cukup sesuai karena keterampilan tiap tenaga pekerja tidak semuanya sama (beragam).

Tabel 2. Blok CA untuk penghitungan EKK

\begin{tabular}{lcc}
\hline \multicolumn{1}{c}{ Area } & Luas (m2) & Tenaga Kerja \\
\hline CA 1 & 54.360 & 12 \\
CA 2 & 45.620 & 9 \\
CA 3 & 55.318 & 10 \\
CA 4 & 47.569 & 12 \\
CA 5 & 55.723 & 13 \\
CA 6 & 50.735 & 11 \\
Pulau Besar dan & 84.757 & 16 \\
Kecil & 394.082 & 83 \\
\hline Total & & \\
\hline
\end{tabular}

(Sumber: Hasil pengamatan, 2018)

Untuk rata-rata kapasitas pekerjaan/ $\mathrm{m}^{2}$, penulis tidak menggunakan standar oleh Arifin (2000). Karena ketika dihitung, terjadi ketidaksesuaian hasil dari jumlah tenaga kerja yang dibutuhkan (penambahan tenaga mencapai 2 kali lipat), dan juga terdapat pekerjaan yang belum ada standarnya, oleh karena itu penulis menghitung hasil rata-rata kapasitas pekerjaan $/ \mathrm{m}^{2}$ dari 3 orang sampel pada tiap jenis pekerjaan blok CA (Tabel 3). Setelah semua data didapatkan, maka dilakukan penghitungan Total Jam Kerja (TJK) selama satu bulan pada blok CA kawasan The Nusa Dua (Tabel 4).

Dari hasil perhitungan setiap bulannya dibutuhkan $16.396,59$ jam kerja, dalam waktu satu bulan tiap pekerja pemeliharaan pada blok CA ini bekerja selama 168 jam. Dengan diketahuinya jam kerja perorang dan rata-rata jam kerja untuk semua pekerjaan dalam waktu satu bulan, maka unuk luasan CA kawasan The Nusa 
Dua yang dipelihara membutuhkan sekiranya 98 pekerja (Tabel 5). Rasio tenaga kerja akan turun menjadi 1:0,4 dengan arti untuk satu orang pekerja memiliki area yang harus dipelihara seluar 0,4 ha.

Tabel 3. Perbandingan Standar Kapasitas Pekerjaan

\begin{tabular}{clcc}
\hline No & \multicolumn{1}{c}{ Jenis Pemeliharaan Taman } & $\begin{array}{c}\text { Kapasitas Kerja } \\
(\text { Arifin, 2000) } \\
\left(\mathrm{m}^{2}\right)\end{array}$ & $\begin{array}{c}\text { Kapasitas } \\
\text { Kerja (Hasil } \\
\text { Analisis }) \\
\left(\mathrm{m}^{2}\right)\end{array}$ \\
\hline 1 & Pembersihan/ penyapuan rumput & 400 & 770 \\
\hline 2 & Pembersihan/ Penyapuan perkerasan & 800 & 1037 \\
\hline 3 & $\begin{array}{l}\text { Penyiraman rumput dan tanaman } \\
\text { penutup tanah dengan selang plastik } 3 / 4 \\
\text { inci }\end{array}$ & 150 & 143 \\
\hline 4 & $\begin{array}{l}\text { Pemangkasan rumput dengan mesin } \\
\text { diduduki }\end{array}$ & - & 2400 \\
\hline 5 & $\begin{array}{l}\text { Pemangkasan rumput dengan mesin } \\
\text { dorong rover }\end{array}$ & 500 & 1395 \\
\hline 6 & $\begin{array}{l}\text { Pemangkasan rumput dengan mesin } \\
\text { gendong }\end{array}$ & 250 & 811 \\
\hline 7 & $\begin{array}{l}\text { Pemangkasan tanaman semak dan } \\
\text { penutup tanah dengan gunting pangkas }\end{array}$ & 10 & 24 \\
\hline 8 & Penggemburan border semak & - & 563 \\
\hline 9 & $\begin{array}{l}\text { Penyiangan dan penggemburan tanaman } \\
\text { semak dan penutup tanah dengan kored }\end{array}$ & 40 & $\begin{array}{l}\text { Pemupukan pupuk organik pada } \\
\text { tanaman dan penutup tanah }\end{array}$ \\
\hline 10
\end{tabular}

(Sumber: Hasil analisis, 2018)

Tabel 4. Kapasitas Kerja dan Kebutuhan Waktu Pelaksanaan Pemeliharaan Common Area selama satu bulan

\begin{tabular}{|c|c|c|c|c|c|}
\hline No & Uraian Pekerjaan & $\begin{array}{l}\text { Volume } \\
\text { Pekerjaan } \\
\quad(\mathrm{m} 2)\end{array}$ & $\begin{array}{l}\text { Kapasitas } \\
\text { Pekerjaan/ } \\
\text { jam (m2) }\end{array}$ & $\begin{array}{l}\text { Pelaksanaan/ } \\
\text { bulan (kali) }\end{array}$ & $\begin{array}{c}\text { Rata-rata } \\
\text { Pelaksanaan/ } \\
\text { bulan (jam) }\end{array}$ \\
\hline \multirow[t]{3}{*}{1} & Penyiraman & & & & \\
\hline & Widelia & 12488 & 143 & 30 & 2611,57 \\
\hline & Semak, Pohon & 24382 & 143 & 30 & 5099,22 \\
\hline \multirow[t]{6}{*}{2} & Pemangkasan & & & & \\
\hline & Rumput & 172923 & & & \\
\hline & $\begin{array}{l}\text { a. Mesin di } \\
\text { duduki }\end{array}$ & 86462 & 2400 & 1,5 & 54,04 \\
\hline & b. Mesin dorong & 51877 & 1395 & 1,5 & 55,77 \\
\hline & c. Mesin gendong & 34585 & 571 & 1,5 & 90,78 \\
\hline & Semak & 24383 & 81 & 1,5 & 451,53 \\
\hline \multirow[t]{2}{*}{3} & Penyiangan & & & & \\
\hline & Semak & 24383 & 24 & 2 & 2031,92 \\
\hline \multirow[t]{2}{*}{4} & Penggemburan & & & & \\
\hline & Border semak & 4463 & 36 & 1 & 123,97 \\
\hline \multirow[t]{3}{*}{5} & Pemupukan & & & & \\
\hline & Semak & 37237 & 563 & 0,16 & 10,59 \\
\hline & Rumput & 172933 & 563 & 0,08 & 24,59 \\
\hline \multirow[t]{3}{*}{6} & Pembersihan & & & & \\
\hline & Jalan & 38905 & 1037 & 30 & 1125,56 \\
\hline & Rumput & 121046 & 770 & 30 & 4717,04 \\
\hline \multicolumn{5}{|c|}{ Total jam kerja dalam waktu satu bulan } & 16396,59 \\
\hline \multicolumn{5}{|c|}{ Total tenaga yang dibutuhkan } & 98 \\
\hline
\end{tabular}

(Sumber: Hasil analisis, 2018) 
Tabel 5. Jumlah Tenaga Kerja yang Dibutuhkan Berdasarkan EKK

\begin{tabular}{clccc}
\hline No & Area & $\begin{array}{c}\text { Total } \\
\text { Jam } \\
\text { Kerja }\end{array}$ & $\begin{array}{c}\text { Jumlah Tenaga } \\
\text { Eksisting }\end{array}$ & $\begin{array}{c}\text { Jumlah Tenaga } \\
\text { menurut EKK }\end{array}$ \\
\hline 1 & CA 1 & 2175,60 & 12 & 13 \\
\hline 2 & CA 2 & 3239,30 & 9 & 19 \\
\hline 3 & CA 3 & 2590,30 & 10 & 15 \\
\hline 4 & CA 4 & 1856,88 & 12 & 11 \\
\hline 5 & CA 5 & 2542,41 & 13 & 15 \\
\hline 6 & CA 6 & 2017,73 & 11 & 8 \\
\hline 7 & Pulau Peninsula & 1306,57 & 10 & 5 \\
\hline 8 & Pulau Nusa & 865,19 & 6 & 98 \\
\hline \multicolumn{7}{c}{ Total } & 83 & \\
\hline
\end{tabular}

(Sumber: Hasil analisis, 2018)

Berdasarkan hasil penghitungan diatas, untuk mendekati standar ideal pemeliharaan kawasan memang dibutuhkan penambahan jumlah pekerja total sebanyak 15 orang yang tersebar pada beberapa blok CA untuk meningkatkan keefektifan kegiatan pemeliharaan, sedangkan untuk pengurangan tenaga kerja sebanyak 2 orang pada blok Pulau Peninsula dan 1 orang pada blok Pulau Nusa Dharma tidak begitu perlu dilakukan karena blok ini memang membutuhkan sejumlah tenaga karena aktivitas pengunjung yang begitu padat.

Dalam keadaan saat ini dengan total 83 pekerja sebenarnya sudah cukup memenuhi standar pengelolaan ideal, jika tidak ingin dilakukan penambahan jumlah tenaga kerja, maka perlu dilakukan evaluasi keterampilan pekerja dalam kegiatan pemeliharaan kawasan dan memaksimalkan jadwal kerja tenaga secara rinci agar hasil yang dicapai dapat lebih maksimal di masa-masa yang akan datang.

\section{Simpulan}

Secara umum kegiatan pemeliharaan oleh tenaga blok CA sudah cukup mendekati standar ideal pemeliharaan kawasan, walaupun masih terdapat beberapa kendala dalam kegiatan pemeliharaan. Diperlukan evaluasi keterampilan, pemaksimalan jadwal kerja dan penertiban penggunaan peralatan K3 selama pekerjaan berlangsung. Rasio tenaga kerja yang ditetapkan The Nusa Dua adalah $0,47 \mathrm{Ha}$, yang artinya tiap satu orang pekerja memiliki area yang harus dipelihara seluas $0,47 \mathrm{Ha}$. Standar kapasitas pekerjaan/jam $\left(\mathrm{m}^{2}\right)$ dari hasil analisis menggunakan sampel pekerja CA menunjukan hasil yang lebih sesuai. Dari hasil analisis EKK dibutuhkan sekiranya 98 orang untuk mendapat hasil pemeliharaan yang efektif dan efisien. Dengan total 98 pekerja rasio tenaga kerja akan turun menjadi 1:0,4.

\section{Daftar Pustaka}

Dlukha, S., S. Wardiningsih, Y. Febriani, R.M. Syahadat, dan P.T. Putra. (2017). Pemeliharaan hazard di Padang Golf Matoa Nasional, Jakarta Selatan. Buana Sains, 17 (2):115-124.

Febriani, Y. (1998). Pemeliharaan lanskap Common Area di Kawasan Wisata Nusa Dua, Bali. Laporan Keterampilan Profesi (Unpublished). Institut Pertanian Bogor.

ITDC. (2017). Annual Report 2017 PT Pengembangan Pariwisata Indonesia (Persero) Indonesia Tourism Development Corporation (ITDC).

Putra, P. T., Syahadat, R. M., Radnawati, D., \& Nurisjah, S. (2017). Buku Panduan Pengelolaan Taman Kota Depok, IALI, Jakarta

Wijayanti, B.R. (2000). Pemeliharaan Lanskap Common Area di Kawasan Pariwisata Nusa Dua, Bali. Skripsi. Jurusan Budi Daya Pertanian, Fakultas Pertanian, Institut Pertanian Bogor. 